\title{
Risk of HBV Reactivation in Patients Infected with HBV/HCV Treated with DAA
}

\author{
Malgorzata Pawlowska, ${ }^{1, *}$ and Krzysztof Domagalski ${ }^{2}$ \\ ${ }^{1}$ Department of Paediatric Infectious Diseases and Haepatology, Faculty of Medicine, Nicolaus Copernicus University, Bydgoszcz, Poland \\ ${ }^{2}$ Centre for Modern Interdisciplinary Technologies, Nicolaus Copernicus University, Torun, Poland \\ "Corresponding author: Malgorzata Pawlowska, Department of Paediatric Infectious Diseases and Haepatology, Faculty of Medicine, Collegium Medicum Bydgoszcz, Nicolaus \\ Copernicus University Torun, Floriana 12, Bydgoszcz, Poland. Tel: +48-523255605, Fax: +48-523255650, E-mail: mpawlowska@cm.umk.pl
}

Received 2017 April 30; Revised 2017 May 30; Accepted 2017 August 28.

\begin{abstract}
The exact number of HBV/HCV co-infected patients is unknown. In many cases of HBV/HCV co-infection, HCV inhibits replication of HBV. After treatment and eradication of the dominant virus, the other one may then become active. The overall dominant effect appears to be hepatitis $\mathrm{C}$ over hepatitis B. Therefore, when planning treatment for eradication of HCV, the risk of HBV reactivation should be taken into account. In interferon-based therapies of patients with $\mathrm{HBV} / \mathrm{HCV}$ co-infection, some cases of HBV reactivation without hepatitis were observed because IFN is effective against both viruses. In contrast, DAA treatment of hepatitis C in $\mathrm{HBV} / \mathrm{HCV}$ co-infection is not well established. Currently, no clinical trials have been published regarding treatment of HBV/HCV co-infected patients with HCV DAA therapy. There is several research on HCVDAA therapy in HBV/HCV co-infection, which describes cases of HBV reactivation during and after DDA therapy for HCV. Result of the first available studies demonstrated that patients with HBV/HCV co-infection treated with DAA against HCV should be monitored for HBV reactivation during and after DAA treatment, even though HBV may be inactive at the time of treatment initiation.
\end{abstract}

Keywords: Hepatitis B Virus, Hepatitis C Virus, HBV/HCV Co-Infection, HBV Reactivation, Direct-Acting Antiviral

\section{Context}

Hepatitis B virus (HBV) and hepatitis C virus (HCV) infections are the most common causes of chronic liver diseases worldwide, including liver cirrhosis, end-stage liver disease, and hepatocellular carcinoma (HCC). It is estimated that approximately 240 - 350 million people are infected with HBV and 71 - 115 million with HCV (1, 2 ). HBV and HCV share the same modes of transmission and $\mathrm{HBV} / \mathrm{HCV}$ co-infection is a frequent occurrence, especially in areas endemic for both viruses and among subjects with high risk of parenteral infections. The number of patients with HBV/HCV co-infection is unknown. Testing for HBsAg alone may substantially underestimate the true prevalence of $\mathrm{HBV} / \mathrm{HCV}$ co-infection with the phenomenon of silent/occult HBV infection (3). The rates of HCV coinfection in HBsAg positive patients vary from 9 to $30 \%$, depending on geographic region (4). In Yu et al. study, $8.4 \%$ of patients with chronic HCV infection were co-infected with $\operatorname{HBV}(5)$.

The analysis of data from national veterans affairs clinical case registry revealed that among 168,239 patients with HCV exposure, 58,415 patients had also HBV exposure giving the prevalence of $34.7 \%$, and among 102,971 patients with HCV infection, 1,431 patients had also HBV co-infection giving the prevalence of 1.4\% (6). In Bini et al. observations,
$61.5 \%$ of 1,257 patients with chronic HCV infection had evidence of prior exposure to HBV, whereas 5.8\% had dual infection with $\mathrm{HBV}$ (7). The incidence of the presence of isolated anti-Hepatitis B core antibodies (HBcAb) in HCV infected patients may be higher because screening programs require often only test for $\mathrm{HBsAg}(3,7)$. According to Wang et al. study, the prevalence of occult HBV infection (OBI) defined as the presence of HBV DNA in the absence of HBsAg has been estimated from 11.9 to $44.4 \%$ of HCV infected cases (8).

Recently, predictors or risk factors of HBV co-infection in HCV infected patients have been identified. In Tyson et al. study, multivariable logistic regression revealed age less than 50 years, male sex, HIV infection, history of hemophilia and thalassemia, history of blood transfusion, and cocaine use as independent risk factors of HBV coinfection (6). In Bini et al. study, among the independent risk factors for $\mathrm{HBV} / \mathrm{HCV}$ dual infection, there were age less than 40 years, Asian ethnicity, intravenous drug use, and a greater number of sexual partners (7).

Several experimental and clinical studies have investigated the interactions between both HBV and HCV viruses. It was revealed that HBV and HCV are capable of suppressing replication of one another and HCV infection can suppress $\mathrm{HBV}$ replication $(7,9)$. In patients co-infected with HBV and HCV, most often lower HBV DNA levels and de-

Copyright (c) 2017, Hepatitis Monthly. This is an open-access article distributed under the terms of the Creative Commons Attribution-NonCommercial 4.0 International License (http://creativecommons.org/licenses/by-nc/4.0/) which permits copy and redistribute the material just in noncommercial usages, provided the original work is properly cited. 
creased hepatic expression of HBsAg and HBcAg compared to mono-infection with HBV were observed. It was the basis for the hypothesis that there are reciprocal interactions between HBV and HCV, where HBV replication is inhibited by $\operatorname{HCV}(10)$.

Many clinical studies have shown that HBV/HCV coinfection compared to HBV or HCV infection alone is associated with faster progression of hepatic fibrosis, more severe liver disease with higher risk of liver cirrhosis, hepatic decompensation, and HCC. In Bini et al. study, comparing HBV/HCV co-infected patients with HCV-mono-infected patients, higher ALT activity, higher necro-inflammatory score, more advanced fibrosis with faster fibrosis rate, and more severe steatosis were observed in histopathological liver pictures of patients with co-infection (5). Since patients with $\mathrm{HBV} / \mathrm{HCV}$ co-infection are at high risk of liver cirrhosis and HCC, they should be given priority in qualification to antiviral treatment.

\section{Evidence Acquisition}

To find relevant studies reporting HBV reactivation in $\mathrm{HBV} / \mathrm{HCV}$ co-infection during anti-HCV therapies, a comprehensive search was conducted on all peer-reviewed journals indexed in PubMed, Scopus, and Web of Science databases. Papers were considered using the appropriate combinations of the following key terms: $\mathrm{HBV} / \mathrm{HCV}$ co-infection, HBV reactivation, direct-acting antiviral, and anti-HCV therapy.

Furthermore, latest HCV management guidelines from the AASLD/IDSA and European Medicines agency (EMA) recommendations were added to compare the obtained findings and support the importance of reactivation of $\mathrm{HBV}$ during anti-HCV treatment.

\section{Results}

\subsection{HBV Reactivation}

Reactivation of hepatitis B is defined as an abrupt reappearance or rise of HBV DNA serum level in patients with previously resolved or inactive $\mathrm{HBV}$ infection. Reactivation of $\mathrm{HBV}$ infection in HBsAg positive patients treated with immunosuppressive or cytotoxic treatment is well known (11-13). Reactivation in patients with resolved HBV infection (HBsAg negative, anti-HBc positive) can also occur during and after immunosuppressive or cytotoxic therapy. According to the hypothesis of reciprocal interactions between HBV and HCV and suppression HBV replication by $\mathrm{HCV}$, the risk of $\mathrm{HBV}$ reactivation following successful $\mathrm{HCV}$ treatment seems to be important.

\subsection{HBV Reactivation During IFN-Based Therapy for HCV}

Because IFN can suppress both HBV and HCV replication, HBV reactivation occurs rarely during IFN-based antiHCV therapies. However, HBV reactivation has been reported during and after treatment with Pegylated Interferon plus Ribavirin (PegIFN+RBV) in patients chronically infected with HBV and HCV. In one report, the reappearance of HBV DNA during treatment with PegIFN + RBV was present in $38 \%$ of $\mathrm{HBV} / \mathrm{HCV}$ co-infected patients with pretreatment serum HBV DNA $<200 \mathrm{IU} / \mathrm{mL}$. None of the recurrent HBV DNA replications was associated with hepatitis flare and none of patients received anti-HBV therapy. In the described study, no clinical hepatitis B developed, and in $30 \%$ of patients, the HBsAg seroconversion was observed. The results of this study suggest that interferon-based therapy may suppress replication of both HCV and HBV viruses (14).

Vigano et al. assessed the risk of HBV reactivation in $22 \mathrm{HBV}$ carriers co-infected with HCV treated with IFN and ribavirin (15). During the treatment, serum HBVDNA, HCV RNA, and ALT activity were evaluated every 3-6 months. Sustained HCV viral response was observed in 9/22 patients, and an increase of serum HBV DNA without ALT activity increase was observed in 3 patients. The authors concluded that the risk of HBV reactivation during and after combined (IFN + RBV) treatment was low.

In a meta-analysis of five trials involving 705 Asian patients, performed by Liu et al. to comparatively analyze the response to interferon plus ribavirin treatment in patients with $\mathrm{HBV} / \mathrm{HCV}$ co-infection and HCV mono-infection, end-of-treatment virological response (ETVR), sustained virological response (SVR), and ALT normalization rate were assessed (9). The rates of ETVR and SVR in both groups of patients were comparable. At the end of follow-up, ALT normalization rates were significantly higher in patients with HCV mono-infection than in patients with $\mathrm{HBV} / \mathrm{HCV}$ co-infection $(\mathrm{P}=0.001)$. Serum HBV DNA levels and the rate of HBV DNA resurgence in $\mathrm{HBV} / \mathrm{HCV}$ co-infected patients were significantly higher in patients achieving SVR compared to those treated without SVR $(\mathrm{P}=0.009)$.

Wahle et al. evaluated the HBV reactivation after HCV treatment in 10 hemodialysis patients with $\mathrm{HBV} / \mathrm{HCV}$ coinfection (HBV DNA lower than 2,000 IU/mL) treated with interferon-alpha and followed them up at least 36 months after HCV treatment (16). HBV reactivation during followup was observed in 6/10 patients including 5/6 patients with SVR. Patients with HBV reactivation received lamivudine. The authors concluded that treatment of hepatitis $\mathrm{C}$ in $\mathrm{HBV} / \mathrm{HCV}$ co-infected hemodialysis patients may favor $\mathrm{HBV}$ reactivation and therefore, they recommended monitoring of HBV viremia and implementation of anti-HBV therapy. 
In Chen et al. meta-analysis, the pooled incidence rate of $\mathrm{HBV}$ reactivation among $779 \mathrm{CHC}$ patients with overt HBV was similar among patients treated with IFNbased therapy (14.5\%) and those treated with DAAs (12.2\%) although there was more clinically significant hepatitis due to $\mathrm{HBV}$ reactivation in those treated with pan-oral DAAs compared to those treated with interferon-based therapy. HBV reactivation occurred much earlier in patients treated with IFN-free DAA-based therapy (mostly between 4-12 weeks during treatment) compared to those treated with IFN-based therapy (after the end of follow-up) (17).

\subsection{HBV Reactivation During IFN-Free Therapy for HCV}

The experiences with treatment of chronic hepatitis $C$ with IFN-free direct-acting antiviral (DAA) therapies in patients with $\mathrm{HBV} / \mathrm{HCV}$ co-infection are very limited because of the exclusion criteria of many clinical studies.

In real-life treatment, some causes of $\mathrm{HBV}$ reactivation during treatment with various DAA regimens, including simeprevir plus sofosbuvir (with or without ribavirin), daclatasvir plus asunaprevir, and ledipasvir/sofosbuvir were described (10, 18-20).

Collins et al. presented 2 cases of HBV reactivation during treatment with simeprevir and sofosbuvir(18). The first case concerned a 55-year-old man with history of chronic HBV and genotype 1a HCV co-infection, qualified for IFNfree HCV re-therapy after two previous therapies with pegIFN and ribavirin. The patient had compensated cirrhosis with Child-Pugh class A. Pretreatment HCV RNA was 1.3 million IU/mL. HBV DNA - 2,300 IU/mL, ALT- $62 \mathrm{IU} / \mathrm{mL}$, and the presence of hepatitis B e antibody (anti-HBe) in his serum were detected. Treatment with sofosbuvir and simeprevir resulted in a rapid decline in HCV RNA to undetectable values at week 4 . After 7 weeks of treatment, the patient began malaise, nausea, and abdominal pain with jaundice and hepatomegaly. ALT activity increased to 1,495 IU/L, total bilirubin level to $12.2 \mathrm{mg} / \mathrm{dL}$, INR to 1.96 , and HBV DNA to 22 million IU/mL. HCV treatment was discontinued at week 8 and treatment with tenofovir and emtricitabine was initiated. By week 14, the patient's symptoms resolved and results of LFTs returned to baseline. At week 28, the HCV RNA remained undetectable, and HBV DNA decreased to a level less than $20 \mathrm{IU} / \mathrm{mL}$. Tenofovir and emtricitabine were continued for ongoing HBV suppression.

The second case described by Collins et al. presented a 57-year-old man with history of chronic genotype 1a HCV infection qualified for IFN-free HCV re-therapy (18). Before IFN-free therapy, the HCV RNA serum level was 8.6 million IU/mL, HBV DNA was below the lower limit of quantification (20 IU/mL), and ALT activity was $54 \mathrm{IU} / \mathrm{L}$. HBV serologic studies revealed the serum presence of $\mathrm{HBcAb}$ and $\mathrm{ab}-$ sence of HBsAg and HBsAb. During treatment with sofos- buvir and simeprevir, serum levels of both HBV DNA and HCV RNA were monitored at 2-week intervals. At week 2, serum level of HCV RNA was undetectable and HBV DNA increased to the value of $353 \mathrm{IU} / \mathrm{mL}$. Because of systematic increase of HBV DNA serum level (1,125 IU/mL at week 4), after 4 weeks of treatment, despite normal liver function tests (LFTs) and asymptomatic duration of the disease, tenofovir was added for treatment of HBV reactivation. Serum HCV RNA level remained undetectable and the HCV and HBV viral loads were also undetectable after 12 weeks of therapy. In both patients presented by Collins et al., DAAs therapy led to undetectable HCV RNA after 2 weeks of therapy. Parallel to HCV clearance, significant increases in HBV replication were observed. Both patients had been previously treated with peg-IFN- $\alpha$ and ribavirin without any signs of HBV reactivation. The rapid increase in HBV replication during treatment with sofosbuvir and simeprevir suggests that the risk of HBV reactivation and acute hepatitis may be greater with newer HCV treatment regimens that may concern patients with positive HBcAb but negative HBsAg and HBsAb. The authors explained that the risk of HBV reactivation may be greater with newer HCV treatment regimens (DAA) compared to PegIFN + RBV because of their higher potency against HCV and lack of anti-HBV activity.

Takayama et al. described HBV reactivation in a 69-yearold male with chronic hepatitis HBV/HCV etiology treated with daclatasvir and asunaprevir (20). Before treatment, the serum ALT activity was $94 \mathrm{U} / \mathrm{L}, \mathrm{HCV}$ RNA serum level was $4.2 \log \mathrm{IU} / \mathrm{mL}$, and HBV DNA serum level was $2.5 \log$ copies/mL. During treatment, ALT activity increased to 237 U/L on day 43 in spite of undetectable HCV RNA. Serum HBV DNA increased to $7.0 \log$ copies/mL at the same time. The treatment was stopped due to suspicion of drug-induced liver injury and/or HBV reactivation. Administration of entecavir could reduce HBV DNA serum levels, followed by a decrease in ALT activity. The authors concluded that close monitoring of HBV DNA during anti-HCV DAA therapy and anti-HBV therapy after increased HBV DNA should be considered in patients with $\mathrm{HBV} / \mathrm{HCV}$ co-infection.

De Monte et al. reported a case of early HBV reactivation during DAAs-based anti-HCV treatment (ledipasvir/sofosbuvir) in a patient with resolved $\mathrm{HBV}, \mathrm{HCV}$ genotype 4d, and HIV infection (19). The 53-year-old man with controlled HIV infection with antiretroviral therapy achieved HCV RNA below 12 IU/mL at week 8 of IFN-free therapy of chronic hepatitis $C$. When treatment finished, dizziness, fever, jaundice, and increased ALT activity (1,026 U/L) and bilirubin level (174 umol/L) were observed. Serum HBV DNA undetectable at the beginning of therapy increased to $8.9 \log 10 \mathrm{IU} / \mathrm{mL}$. Introduction of tenofovir induced a decrease in HBV DNA while HCV RNA and HIV RNA were still undetectable. In the author's point of view, the described 
case highlights the necessity for close monitoring of HBV infection markers in all patients qualified for HCV DAA therapy.

Ou et al. described hepatitis B reactivation in a 53-yearold man after four weeks of therapy of chronic hepatitis C with ledipasvir/sofosbuvir (21). Serum HCV RNA was undetectable after 3 weeks of IFN-free therapy. At the fourth week, the patient appeared weak, had poor appetite and yellow urine. HBV DNA undetectable at the beginning of treatment increased to $8.26 \mathrm{E} 7 \mathrm{IU} / \mathrm{mL}$, ALT activity increased to $779 \mathrm{U} / \mathrm{L}$, and bilirubin to $90.8 \mathrm{umol} / \mathrm{L}$. The patient received entecavir and showed undetectable HBV DNA after five weeks. The authors proposed simultaneous anti-HBV treatment as a more reasonable option for patients with $\mathrm{HBV} / \mathrm{HCV}$ co-infection treated with DAAs.

The first report of hepatitis $B$ reactivation leading to fulminant hepatic failure and liver transplantation after initiation of IFN-free treatment for hepatitis $\mathrm{C}$ was described by Ende et al. (10). The case concerned a 59-yearold woman with chronic hepatitis $\mathrm{C}$ genotype $\mathrm{b}$ and isolated anti-HBc serum presence, who initiated treatment with simeprevir, sofosbuvir, and ribavirin. She responded very well to treatment with near normalization of ALT, and HCV RNA decreased below the level of quantification after 4 weeks of treatment. At week 11 of the planned 12week course, she developed fulminant hepatic failure due to hepatitis $\mathrm{B}$ reactivation and ultimately required liver transplantation.

Garcia et al. presented the case of a 53-year-old patient co-infected with HIV/HCV who developed acute liver failure and died of HBV reactivation during IFN-free therapy of chronic hepatitis $\mathrm{C}$ with sofosbuvir and ledipasvir (22). Two years earlier, this patient had been treated with pegylated interferon and ribavirin but the therapy was interrupted due to bad tolerance of PegIFN. During DAAs treatment, serum HCV RNA decreased to less than $15 \mathrm{IU} / \mathrm{mL}$ in week 8, and the patient achieved SVR in week 4 of followup. A month later, the patient demonstrated abdominal pain, nausea, and jaundice with increased ALT activity to $1025 \mathrm{IU} / \mathrm{L}$, bilirubin serum level to $10.98 \mathrm{mg} / \mathrm{dL}$, and appearance of HBV DNA. Treatment with entecavir was initiated; however, clinical and laboratory evaluations did not confirm ascites and encephalopathy, and the patient died of acute liver failure.

Yeh et al. evaluated 64 patients with chronic hepatitis C co-infected with HBV, including 7 with current HBV infection and 57 with past HBV infection, treated with pan oral DAA therapy. Compared to patients with past HBV infection, patients with current HBV infection had a significantly lower pre-treatment HCV RNA level $(\mathrm{P}=0.016)$ and higher rate of HBV DNA $(\mathrm{P}=0.001)$. The overall SVR rate was $96.9 \%$ and 2 patients - one from each group - had a relapse.
HBV virological reactivation was observed in 4 out of $7 \mathrm{HB}-$ sAg positive patients. Clinical reactivation was observed in one patient with detectable HBV DNA before treatment that recovered after entecavir administration. No HBV virological reactivation was observed in patients with past HBV infection (23).

These cases raise concern for the risk of severe hepatitis $\mathrm{B}$ reactivation in hepatitis $\mathrm{B}$ and $\mathrm{C}$-co-infected patients or chronic hepatitis C-infected patients with isolated hepatitis B core antibody treated with DAAs for hepatitis C. HBV reactivation may occur irrespective of the HCV genotype or the class of used DAAs. Presented observations suggest that HBV infection should be monitored parallel to DAAs treatment initiation.

Sulkowski et al. found no evidence of HBV reactivation in cohort of 103 patients with HBcAb serum presence examined at post treatment week 24 of therapy with sofosbuvirledipasvir against HCV infection (24). The authors suggested that $\mathrm{HBV}$ reactivation in co-infected patients with $\mathrm{HBcAb}$ without HBsAg is uncommon.

Gane et al. evaluated whether ledipasvir and sofosbuvir therapy could suppress HCV infection in patients coinfected with HBV (25). All eight patients reached HCV RNA $<15$ IU/mL 12 weeks after treatment. In seven of eight patients with SVR, serum HBV DNA levels increased during treatment, but none of the increases was greater than 20,000 IU/mL, and none was associated with clinical HBV flares or required treatment.

In the US food and drug administration (FDA) adverse events reporting system (FAERS) database, 29 cases of HBV reactivation were registered between November 2013 and October 2016 in patients with inactive or resolved HBV infection receiving direct-acting antiviral (DAA) therapy for HCV infection (26). All cases were temporarily associated with DAA initiation. Most of the cases occurred within 4 8 weeks of initiation. HBV reactivation resulted in significant clinical complications including liver functions decompensation in 3 patients, leading to death in 2 patients and liver transplantation in one patient. Initiation of HBV treatment was delayed in 7 of $16(44 \%)$ treated cases. Most patients treated for HBV experienced decreased HBV DNA and improved liver function and clinical symptoms.

\subsection{Risk Factors for HBV Reactivation}

Wang et al. performed an observational study to determine the incidence and factors associated with hepatitis in 327 patients receiving DAAs agents for $\mathrm{HCV}$ infections in areas endemic for HBV in China (8). Among the examined patients, 10 were positive for HBsAg, and 124 had occult HBV infection. In the total study population, 10 patients (3.1\%) had hepatitis. In 3 cases, hepatitis was associated with HBV reactivation including 1 case not in the icteric phase, 1 case 
in the icteric phase, and 1 case with liver failure. The strong risk factor for developing hepatitis during treatment was the presence of HBsAg before DAA treatment $(\mathrm{P}<0.001)$. However, based on the recorded cases, FDA suggests that $\mathrm{HBV}$ reactivation is independent of HCV genotype, DAA use, and baseline HBV disease parameters. Up to now, the mechanism by which HCV-therapy might cause HBV reactivation is not known and there are no genetic markers for prediction of HBV reactivation (26).

\subsection{Recommendations}

Presented data supports the idea that effective elimination of HCV may increase the risk of the shift in immunological control. In part because of this, the latest HCV management guidelines from the AASLD/IDSA now recommend that all patients starting HCV DAA therapy should be assessed for HBV co-infection with HBsAg, anti-HBs, and anti-HBc testing (27). For HBsAg positive patients, the test for HBV DNA should be obtained and patients meeting criteria for HBV treatment should start therapy at the same time or before HCV DAA therapy initiation. According to the same recommendations, patients with low or undetectable HBV DNA levels should be monitored at regular intervals for HBV reactivation. For patients with the presence of anti-HBc alone or for anti-HBs and anti-HBc, the possibility of $\mathrm{HBV}$ reactivation should be considered in case of an increase in LFTs during or after DAAs treatment (Figure 1).

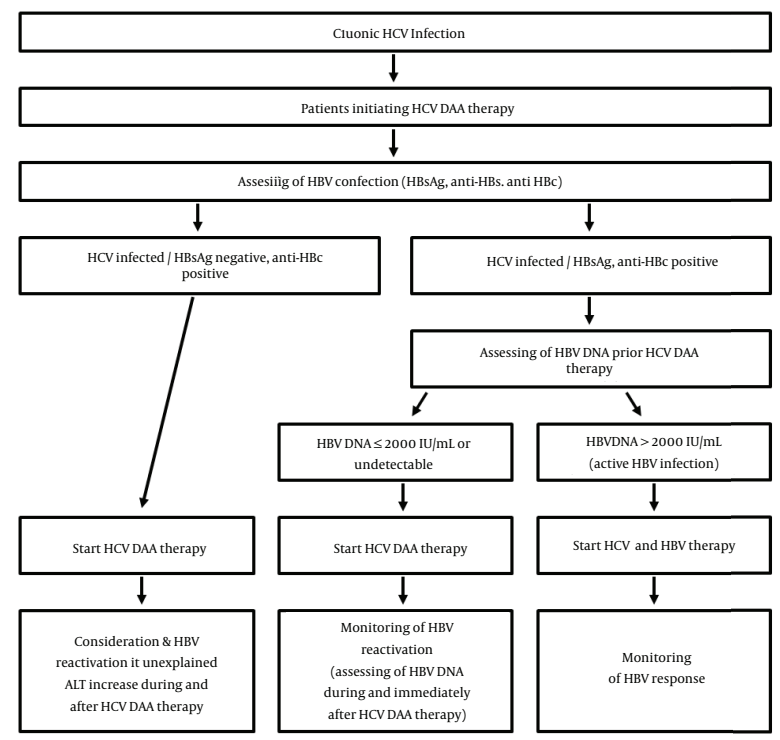

Figure 1. Algorithm for the Management of HBV/HCV Co-Infected Patients Prior to HCV DAA Therapy

On December 2, 2016, the Pharmacovigilance risk as- sessment committee (PRAC) of the European Medicines agency (EMA) issued a news release confirming the risk of $\mathrm{HBV}$ reactivation in patients being treated with DAA agents for HCV (28). On December 16, 2016, the European Medicines agency (EMA) confirmed its recommendation to screen all patients for hepatitis B before starting treatment with direct-acting antivirals for hepatitis C. Patients infected with HCV and HBV must be monitored and managed according to current clinical guidelines (29).

\section{Conclusions}

It seems close monitoring of HBV co-infection by HBV DNA, HBsAg, anti-HBc, and ALT assessment may be warranted during any anti-HCV therapy regardless of the used DAAs class or the HCV genotype. Anti-HBV therapy with nucleoside analogs parallel or after the increase of $\mathrm{HBV}$ DNA should be considered in patients with HBV/HCV coinfection.

\section{Footnotes}

Authors' Contribution: Malgorzata Pawlowska and Krzysztof Domagalski contributed to writing and reviewing of this manuscript; all the authors approved the final version.

\section{Financial Disclosure: No sponsors.}

Role of the Sponsor: The authors declare that they have no conflict of interest regarding this work.

Funding/Support: This study was not financially supported.

\section{References}

1. Gower E, Estes C, Blach S, Razavi-Shearer K, Razavi H. Global epidemiology and genotype distribution of the hepatitis $\mathrm{C}$ virus infection.J Hepatol. 2014;61(1 Suppl):S45-57. doi:10.1016/j.jhep.2014.07.027. [PubMed: 25086286].

2. Polaris Observatory $\mathrm{H}$. Global prevalence and genotype distribution of hepatitis C virus infection in 2015: a modelling study. Lancet Gastroenterol Hepatol. 2017;2(3):161-76. doi: 10.1016/S2468-1253(16)30181-9. [PubMed: 28404132].

3. Chu CJ, Lee SD. Hepatitis B virus/hepatitis C virus coinfection: epidemiology, clinical features, viral interactions and treatment. J Gastroenterol Hepatol. 2008;23(4):512-20. doi: 10.1111/j.14401746.2008.05384.x. [PubMed: 18397482].

4. Crockett SD, Keeffe EB. Natural history and treatment of hepatitis B virus and hepatitis C virus coinfection. Ann Clin Microbiol Antimicrob. 2005;4:13. doi: 10.1186/1476-0711-4-13. [PubMed: 16159399].

5. Yu G, Chi X, Wu R, Wang X, Gao X, Kong F, et al. Replication Inhibition of Hepatitis B Virus and Hepatitis C Virus in Co-Infected Patients in Chinese Population. PLoS One. 2015;10(9):e0139015. doi: 10.1371/journal.pone.0139015. [PubMed: 26422607]. 
6. Tyson GL, Kramer JR, Duan Z, Davila JA, Richardson PA, El-Serag HB. Prevalence and predictors of hepatitis $B$ virus coinfection in a United States cohort of hepatitis C virus-infected patients. Hepatology. 2013;58(2):538-45. doi: 10.1002/hep.26400. [PubMed: 23505059].

7. Bini EJ, Perumalswami PV. Hepatitis B virus infection among American patients with chronic hepatitis $\mathrm{C}$ virus infection: prevalence, racial/ethnic differences, and viral interactions. Hepatology. 2010;51(3):759-66. doi: 10.1002/hep.23461. [PubMed: 20140950].

8. Wang C, Ji D, Chen J, Shao Q, Li B, Liu J, et al. Hepatitis due to Reactivation of Hepatitis B Virus in Endemic Areas Among Patients With Hepatitis C Treated With Direct-acting Antiviral Agents. Clin Gastroenterol Hepatol. 2017;15(1):132-6. doi:10.1016/j.cgh.2016.06.023. [PubMed: 27392759].

9. Liu JY, Sheng YJ, Hu HD, Zhong Q, Wang J, Tong SW, et al. The influence of hepatitis $B$ virus on antiviral treatment with interferon and ribavirin in Asian patients with hepatitis $C$ virus/hepatitis B virus coinfection: a meta-analysis. VirolJ. 2012;9:186. doi: 10.1186/1743-422X-9-186. [PubMed: 22950520].

10. Ende AR, Kim NH, Yeh MM, Harper J, Landis CS. Fulminant hepatitis B reactivation leading to liver transplantation in a patient with chronic hepatitis $C$ treated with simeprevir and sofosbuvir: a case report. J Med Case Rep. 2015;9:164. doi: 10.1186/s13256-015-0630-8. [PubMed: 26215390].

11. Colson P, Borentain P, Coso D, Motte A, Aurran-Schleinitz T, Charbonnier A, et al. Hepatitis $B$ virus reactivation in HBsAg-negative patients is associated with emergence of viral strains with mutated HBsAg and reverse transcriptase. Virology. 2015;484:354-63. doi: 10.1016/j.virol.2015.06.017. [PubMed: 26186574].

12. Kusumoto S, Tanaka Y, Suzuki R, Watanabe T, Nakata M, Takasaki H, et al. Monitoring of Hepatitis B Virus (HBV) DNA and Risk of HBV Reactivation in B-Cell Lymphoma: A Prospective Observational Study. Clin InfectDis. 2015;61(5):719-29. doi:10.1093/cid/civ344. [PubMed: 25935551].

13. Liu CJ, Chen PJ, Chen DS, Kao JH. Hepatitis B virus reactivation in patients receiving cancer chemotherapy: natural history, pathogenesis, and management. Hepatol Int. 2013;7(2):316-26. doi: 10.1007/s12072011-9279-6. [PubMed: 21670970].

14. Yu ML, Lee CM, Chen CL, Chuang WL, Lu SN, Liu CH, et al. Sustained hepatitis $\mathrm{C}$ virus clearance and increased hepatitis $\mathrm{B}$ surface antigen seroclearance in patients with dual chronic hepatitis $\mathrm{C}$ and $\mathrm{B}$ during posttreatment follow-up. Hepatology. 2013;57(6):2135-42. doi: 10.1002/hep.26266. [PubMed: 23322699].

15. Vigano M, Aghemo A, Iavarone M, Rumi MG, Agnelli F, Lampertico P, et al. The course of inactive hepatitis B in hepatitis-C-coinfected patients treated with interferon and ribavirin. Antivir Ther. 2009;14(6):789-96. doi: 10.3851/IMP1284. [PubMed:19812441].

16. Wahle RC, Perez RM, Pereira PF, Oliveira EM, Emori CT, Uehara SN, et al. Hepatitis B virus reactivation after treatment for hepatitis $\mathrm{C}$ in hemodialysis patients with HBV/HCV coinfection. Braz J Infect Dis. 2015;19(5):533-7. doi: 10.1016/j.bjid.2015.04.003. [PubMed: 25997784].

17. Chen G, Wang C, Chen J, Ji D, Wang Y, Wu V, et al. Hepatitis B reactivation in hepatitis $B$ and $C$ coinfected patients treated with antiviral agents: A systematic review and meta-analysis. Hepatology. 2017;66(1):13-26. doi: 10.1002/hep.29109. [PubMed: 28195337].
18. Collins JM, Raphael KL, Terry C, Cartwright EJ, Pillai A, Anania FA, et al. Hepatitis B Virus Reactivation During Successful Treatment of Hepatitis C Virus With Sofosbuvir and Simeprevir. Clin Infect Dis. 2015;61(8):1304-6. doi: 10.1093/cid/civ474. [PubMed: 26082511].

19. De Monte A, Courjon J, Anty R, Cua E, Naqvi A, Mondain V, et al. Directacting antiviral treatment in adults infected with hepatitis $C$ virus: Reactivation of hepatitis B virus coinfection as a further challenge. J Clin Virol. 2016;78:27-30. doi: 10.1016/j.jcv.2016.02.026. [PubMed: 26967675].

20. Takayama H, Sato T, Ikeda F, Fujiki S. Reactivation of hepatitis B virus during interferon-free therapy with daclatasvir and asunaprevir in patient with hepatitis B virus/hepatitis $\mathrm{C}$ virus co-infection. Hepato Res. 2016;46(5):489-91. doi: 10.1111/hepr.12578. [PubMed: 26297529].

21. Ou P, Fang Z, Chen J. Hepatitis B reactivation in a chronic hepatitis C patient treated with ledipasvir and sofosbuvir: A case report. Clin Res Hepatol Gastroenterol. 2017;41(2):e17-8. doi: 10.1016/j.clinre.2016.08.001. [PubMed: 27601170].

22. Garcia MP, Hernandez IL, Cuenca FF, Rios Villegas MJ. Acute B hepatitis after hepatitis $C$ virus therapy with direct acting antivirals in a co-infected patient with HIV. J Liver. 2016;5(3) doi: 10.4172/21670889.1000203.

23. Yeh ML, Huang CF, Hsieh MH, Ko YM, Chen KY, Liu TW, et al. Reactivation of hepatitis $B$ in patients of chronic hepatitis $C$ with hepatitis $B$ virus infection treated with direct acting antivirals. J Gastroenterol Hepatol. 2017 doi: 10.1111/jgh.13771. [PubMed: 28230928].

24. Sulkowski MS, Chuang WL, Kao JH, Yang JC, Gao B, Brainard DM, et al. No Evidence of Reactivation of Hepatitis B Virus Among Patients Treated With Ledipasvir-Sofosbuvir for Hepatitis C Virus Infection. Clin Infect Dis. 2016;63(9):1202-4. doi: 10.1093/cid/ciw507. [PubMed: 27486112].

25. Gane EJ, Hyland RH, An D, Svarovskaia ES, Brainard D, McHutchison JG. Ledipasvir and sofosbuvir for HCV infection in patients coinfected with HBV. Antivir Ther. 2016;21(7):605-9. doi: 10.3851/IMP3066. [PubMed: 27367295].

26. Food and Drug Administration . FDA Drug Safety Communication FDA warns about the risk of hepatitis $B$ reactivating in some patients treated with direct-acting antivirals for hepatitis C [cited November 16]. Available from: http://www.fda.gov/downloads/Drugs/ DrugSafety/UCM523499.pdf.

27. AASLD/ISDA . HCV Guidance: Recommendations for Testing, Managing, and Treating Hepatitis C [cited September 16]. Available from: http://www.hcvguidelines.org.

28. European Medicines Agency (EMA) . PRAC warns of risk of hepatitis B re-activation with direct-acting antivirals for hepatitis C [news release] [cited December 5]. Available from: http://www.ema.europa.eu/docs/en_GB/document_library/Press_ release/2016/12/WC500217496.pdf.

29. European Medicines Agency (EMA) . Direct-acting antivirals for hepatitis C: EMA confirms recommendation to screen for hepatitis B [cited December 16]. Available from: http: //www.ema.europa.eu/docs/en_GB/document_library/Press_ release/2016/12/WC500218204.pdf. 